\title{
Stirling Analysis Comparison of Commercial VS. High-Order
}

Methods
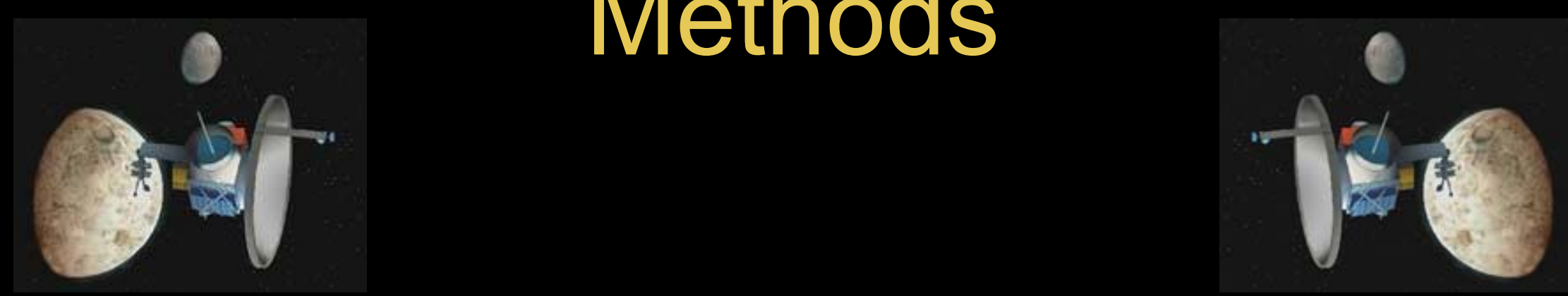

Rodger W. Dyson, Scott D. Wilson

Roy C. Tew, and Rikako Demko

Thermal Energy Conversion Branch

August 15, 2005

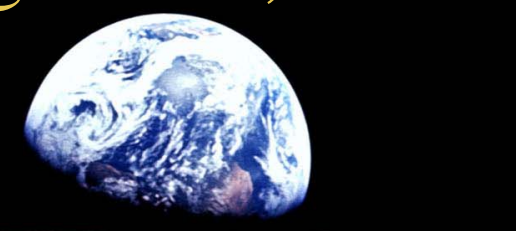




\section{Stirling Simulation Numerical Error}

-Remeshing interpolation

-Layering interpolation

-Diffusive time advance

-Low grid quality/skewness

-Sliding interface interpolation

-Artificial entropy

-Turbulence transition

Schematic with Springs and Dampers

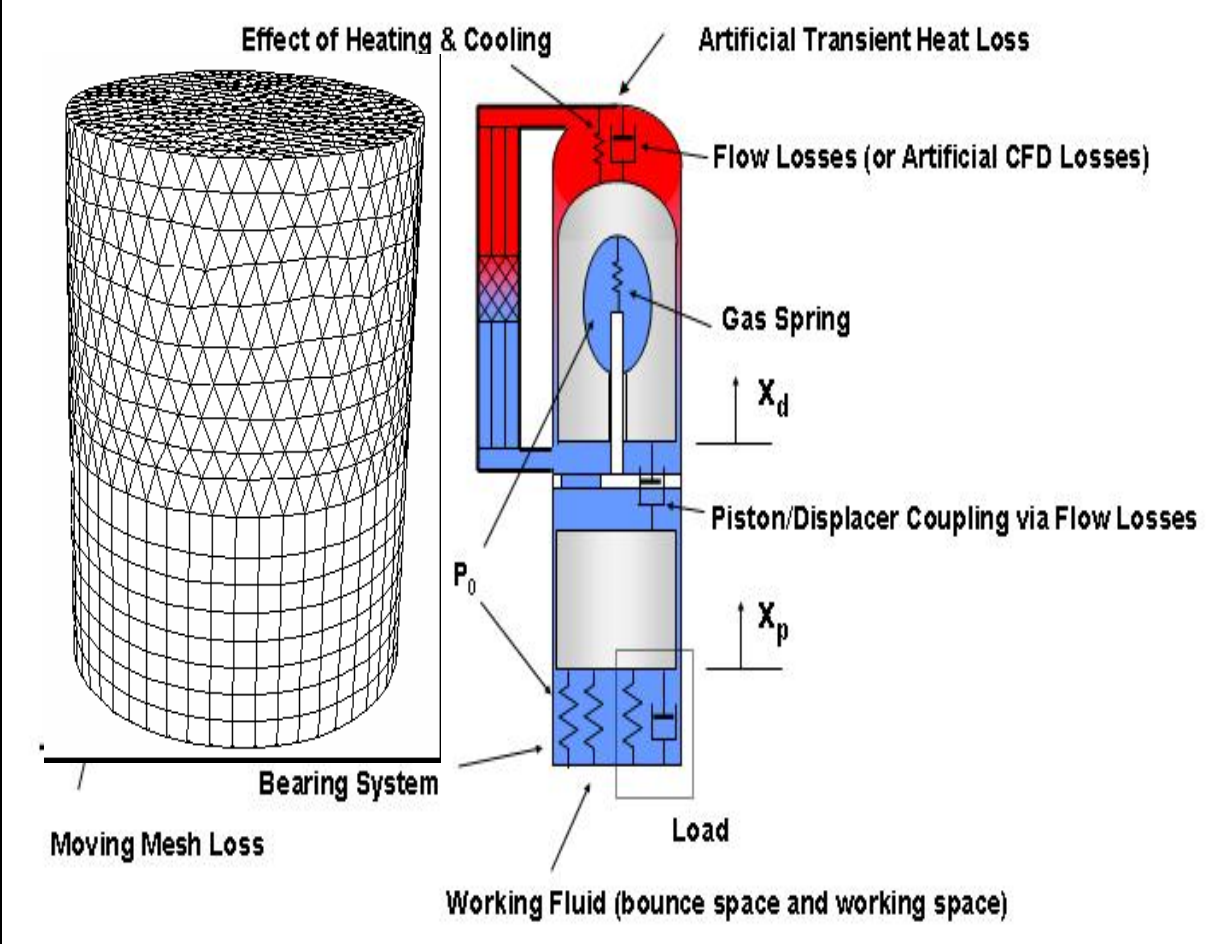

Glenn Research Center at Lewis Field 


\section{Dual Opposed Convertors}

- High Efficiency - Low Mass Space Power

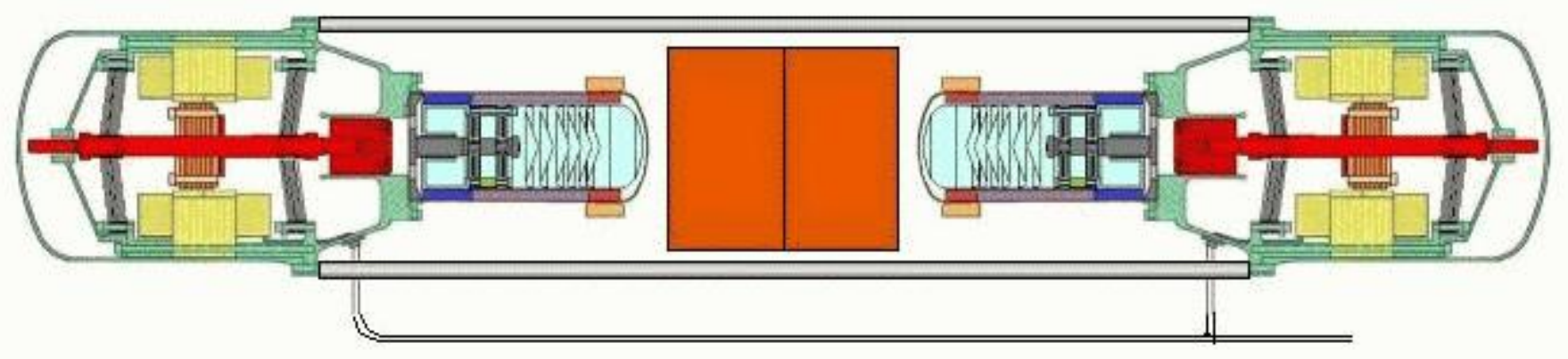

- Free Piston Geometry is Essentially Smooth 


\section{Whole Engine Simulation}

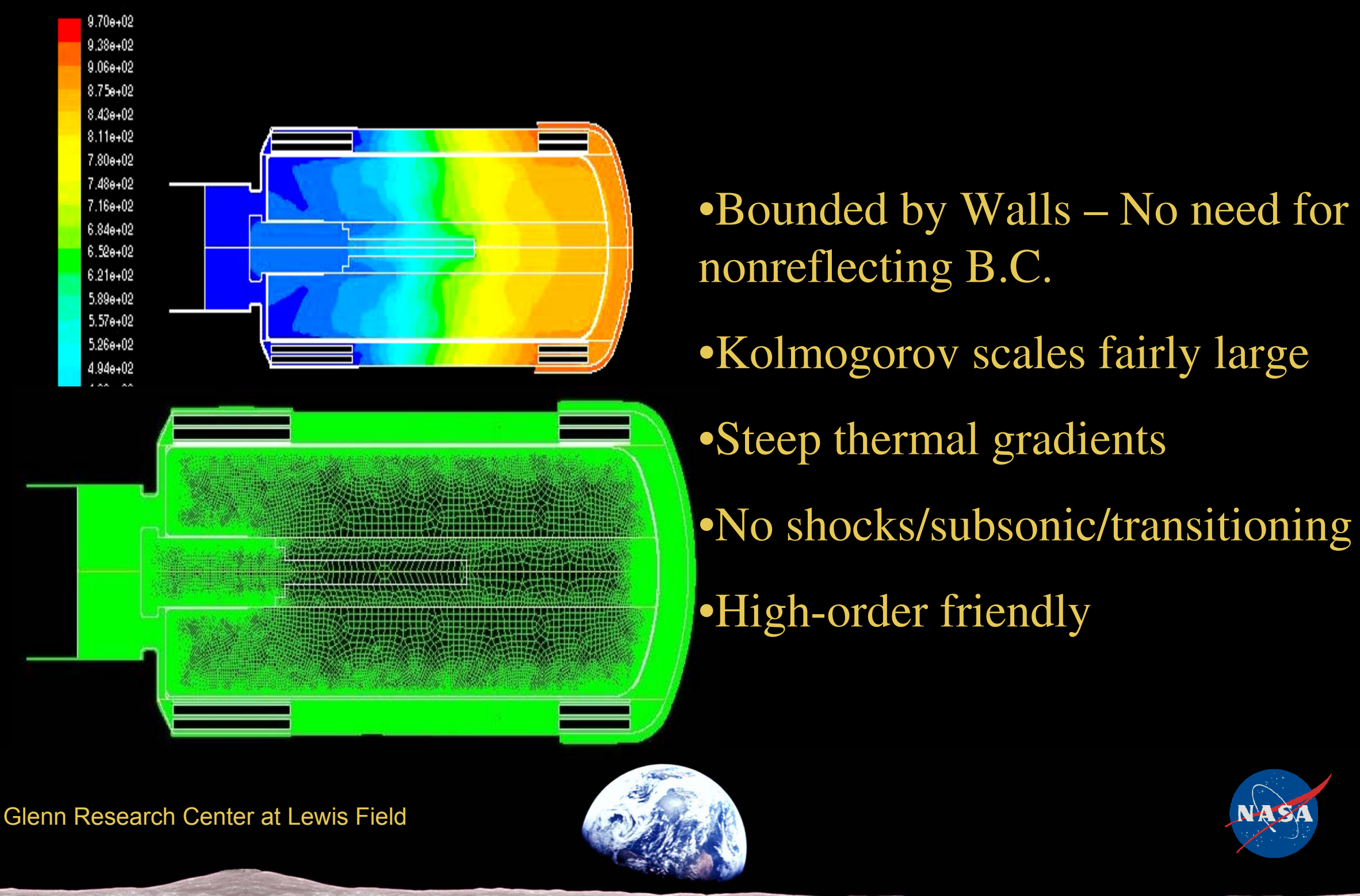




\section{Curvilinear Features}

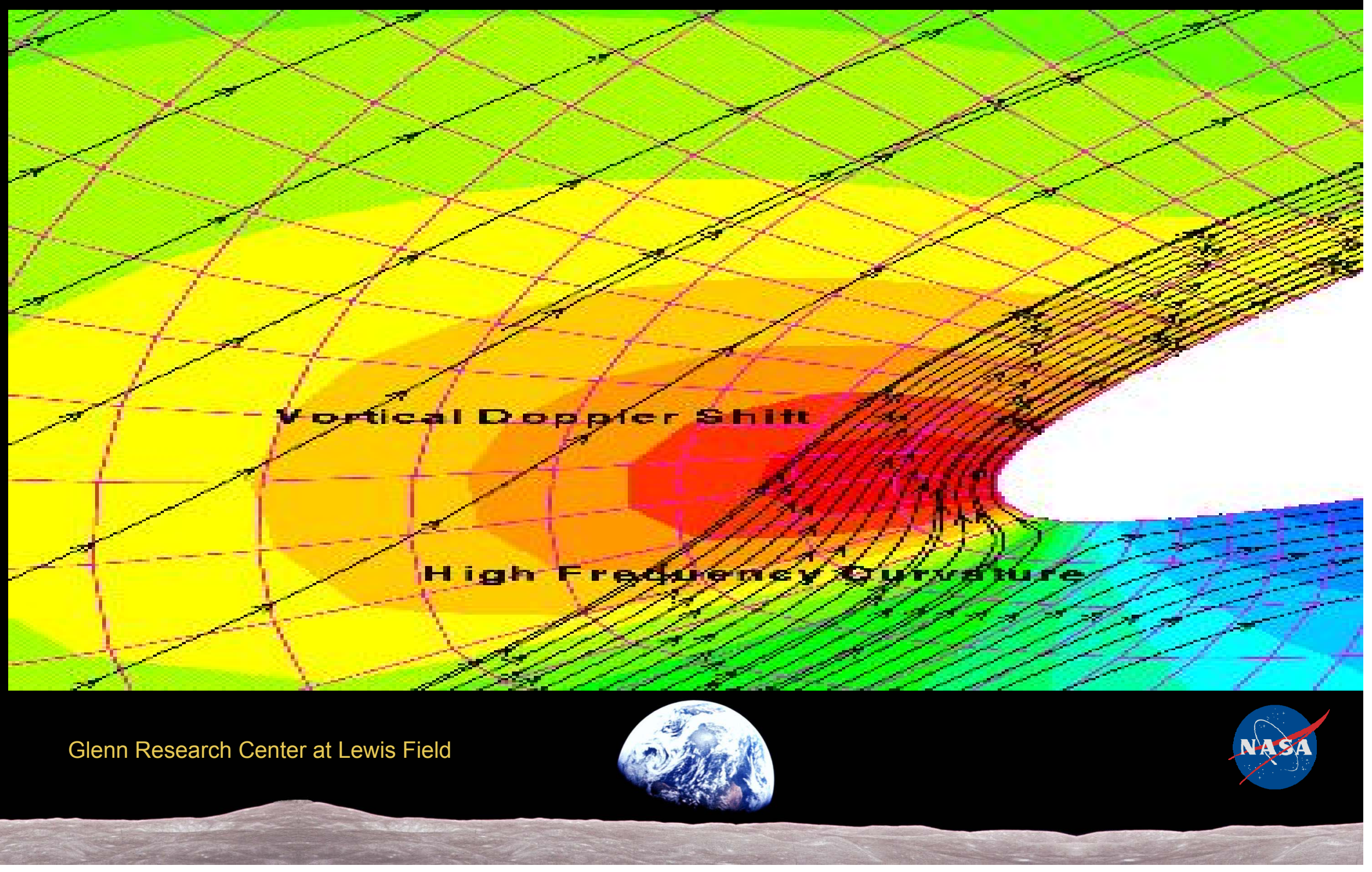




\section{Stability Analysis}

- Courant (CFL) number,

$$
r=c \Delta t / \Delta x
$$

- Von Neumann number, $v=\mu \Delta t / \Delta x^{2}$

- Linear Viscous Burger's Equation

$$
\frac{\partial u}{\partial t}+c \frac{\partial u}{\partial x}=\mu \frac{\partial^{2} u}{\partial x^{2}}
$$




\section{Compact Scheme $6^{\text {th }}$ Order in Space}

$$
\begin{aligned}
& \alpha\left(\frac{\partial u}{\partial x}\right)_{i-1}+\left(\frac{\partial u}{\partial x}\right)_{i}+\alpha\left(\frac{\partial u}{\partial x}\right)_{i+1}=a \frac{u_{i+1}-u_{i-1}}{2 \Delta x}+b \frac{u_{i+2}-u_{i-2}}{4 \Delta x} \\
& \alpha=1 / 3, a=14 / 9, b=1 / 9 \\
& \alpha\left(\frac{\partial^{2} u}{\partial x^{2}}\right)_{i-1}+\left(\frac{\partial^{2} u}{\partial x^{2}}\right)_{i}+\alpha\left(\frac{\partial^{2} u}{\partial x^{2}}\right)_{i+1}=a \frac{u_{i+1}-2 u_{i}+u_{i-1}}{\Delta x^{2}}+b \frac{u_{i+2}-2 u_{i}+u_{i-2}}{4 \Delta x^{2}} \\
& \alpha=2 / 11 a=12 / 11, b=3 / 11
\end{aligned}
$$




\section{Runge-Kutta $4^{\text {th }}$ Order}

$$
\begin{aligned}
& R(u)=-c u_{x}+\mu u_{x x} \\
& u^{(1)}=u^{n}+\frac{\Delta t}{2} R^{n} \\
& u^{(2)}=u^{n}+\frac{\Delta t}{2} R^{1} \\
& u^{(3)}=u^{n}+\Delta t R^{2} \\
& u^{(n+1)}=u^{n}+\frac{\Delta t}{6}\left(R^{n}+2 R^{(1)}+2 R^{(2)}+R^{(3)}\right) \\
& R^{(1)}=R\left(u^{(1)}\right), R^{(2)}=R\left(u^{(2)}\right), R^{(3)}=R\left(u^{(3)}\right)
\end{aligned}
$$




\section{Current Practice}

- Implicit $1^{\text {st }}$ or $2^{\text {nd }}$ order in time commercially

- $1^{\text {st }}$ or $2^{\text {nd }}$ order in space implicit

- Explicit/implicit $4^{\text {th }}$ order in time academically

- Implicit $6^{\text {th }}$ order compact scheme in space 


\section{Compact Scheme Stability Range}

- Domain size affects stability since implicit
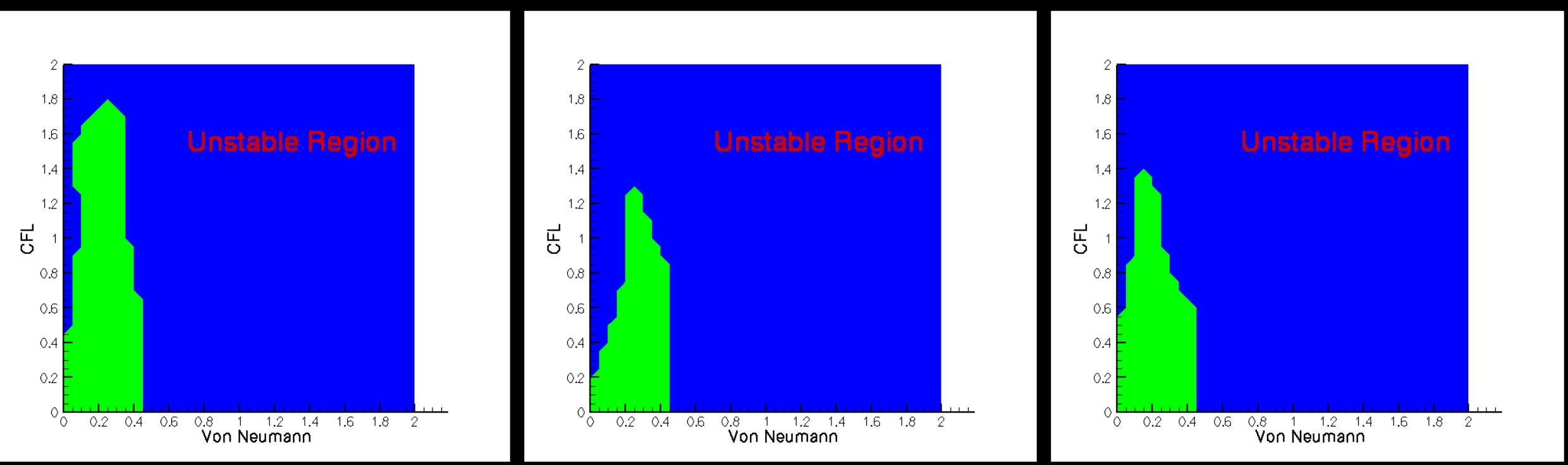


\section{Basic UHF Technique}

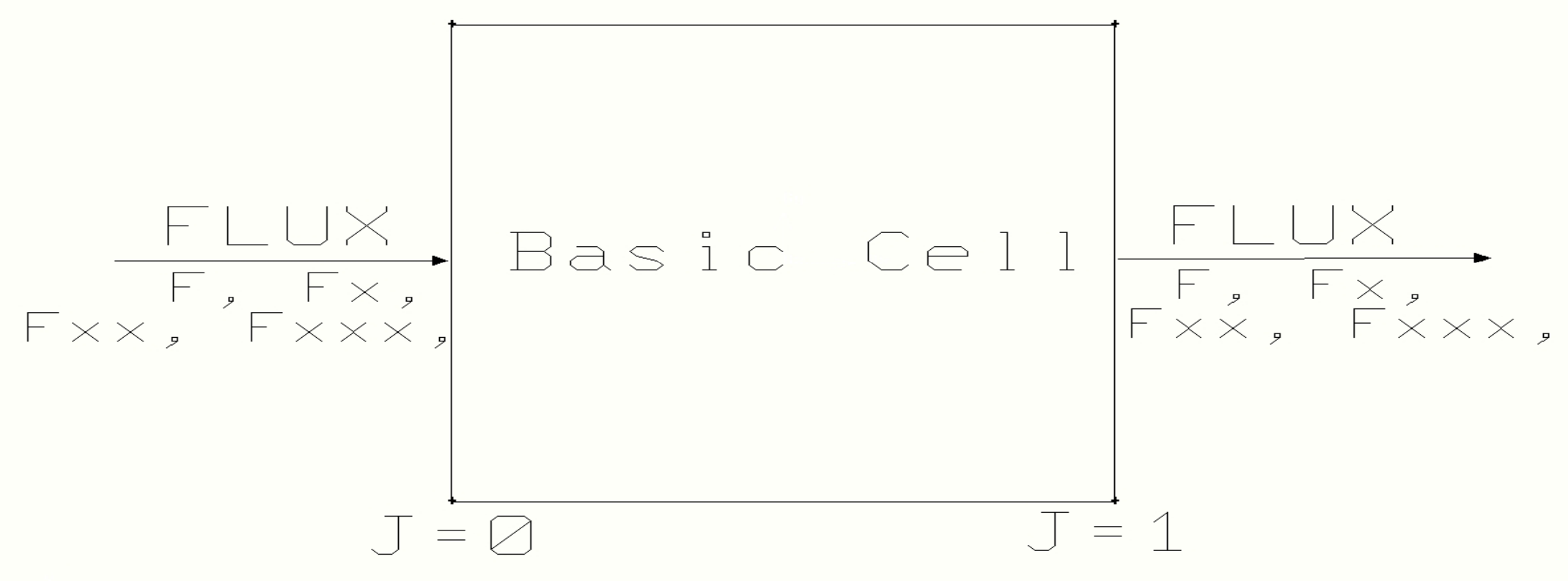




\section{Derivatives of Cell Averages}

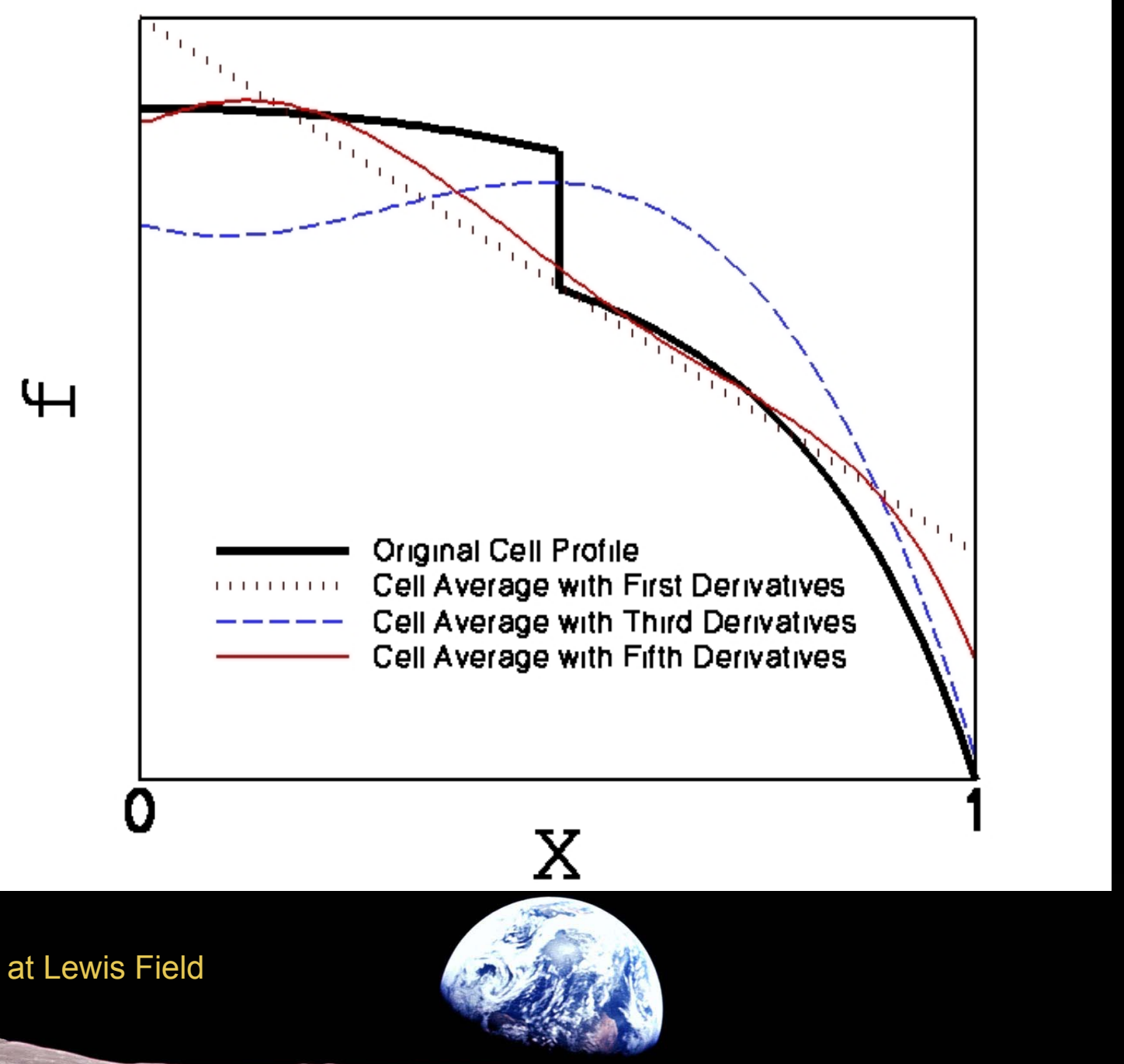




\section{Grid Singularity Resolution}

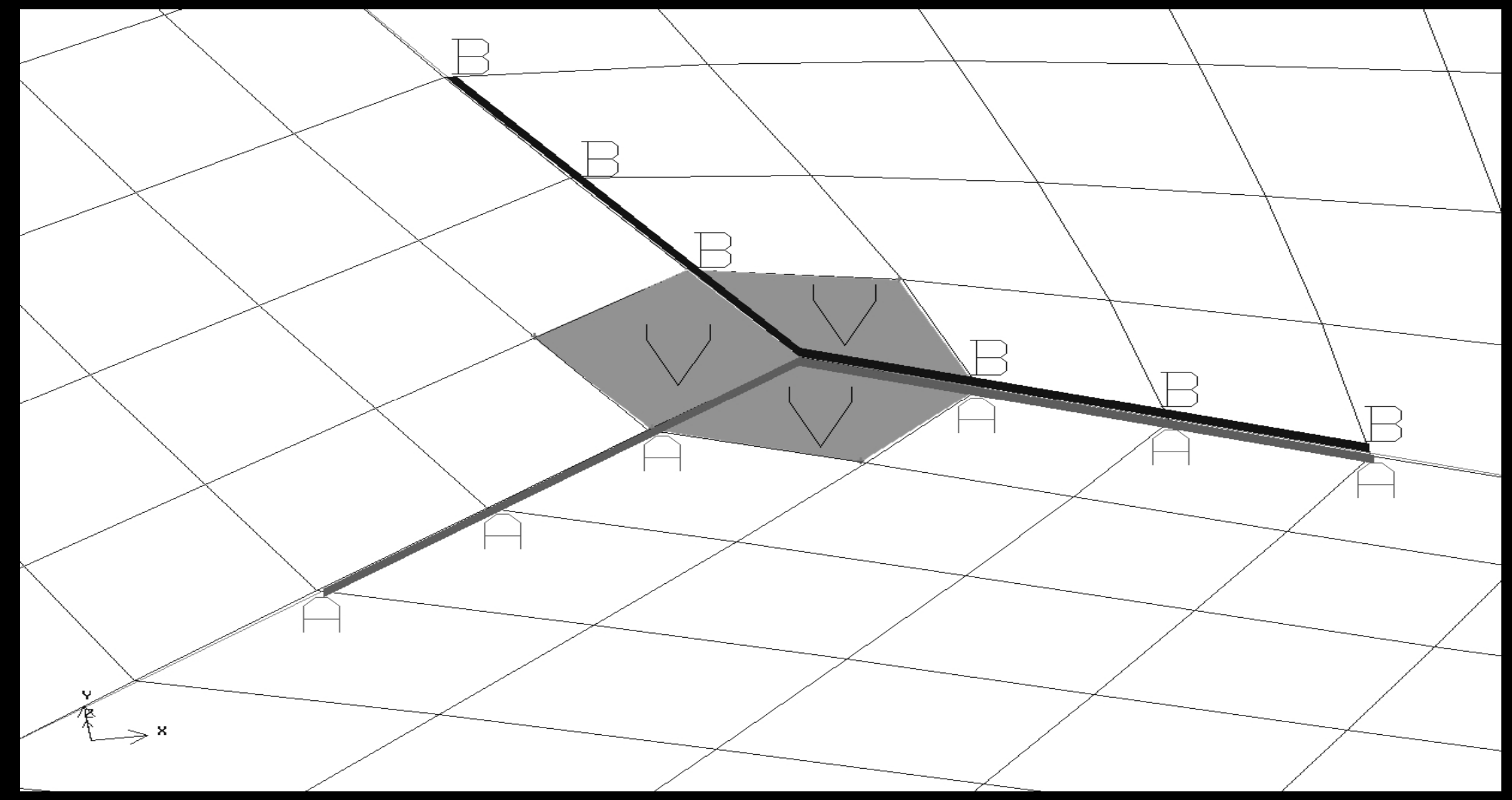




\section{C4o0 Linear Viscous Burger's Equation}
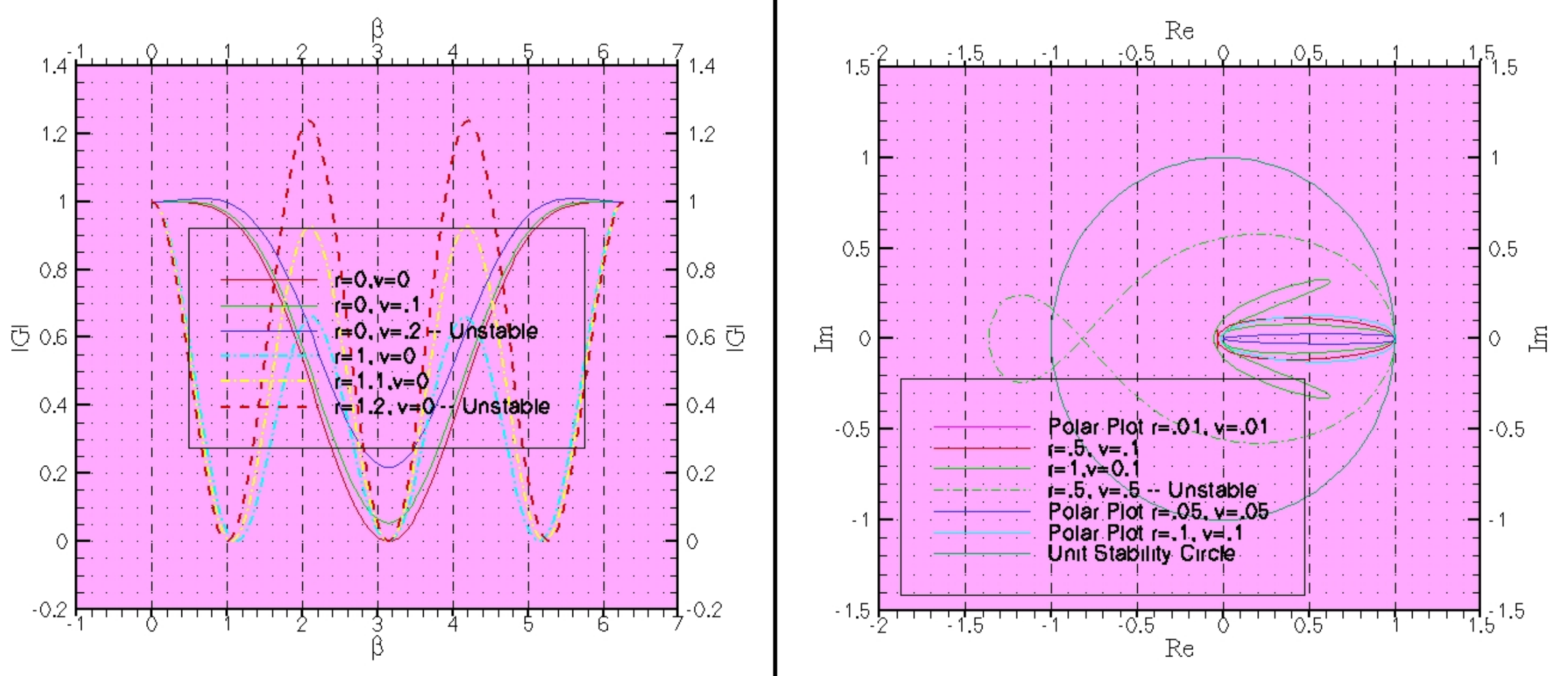


\section{Efficiency Improves with Accuracy}

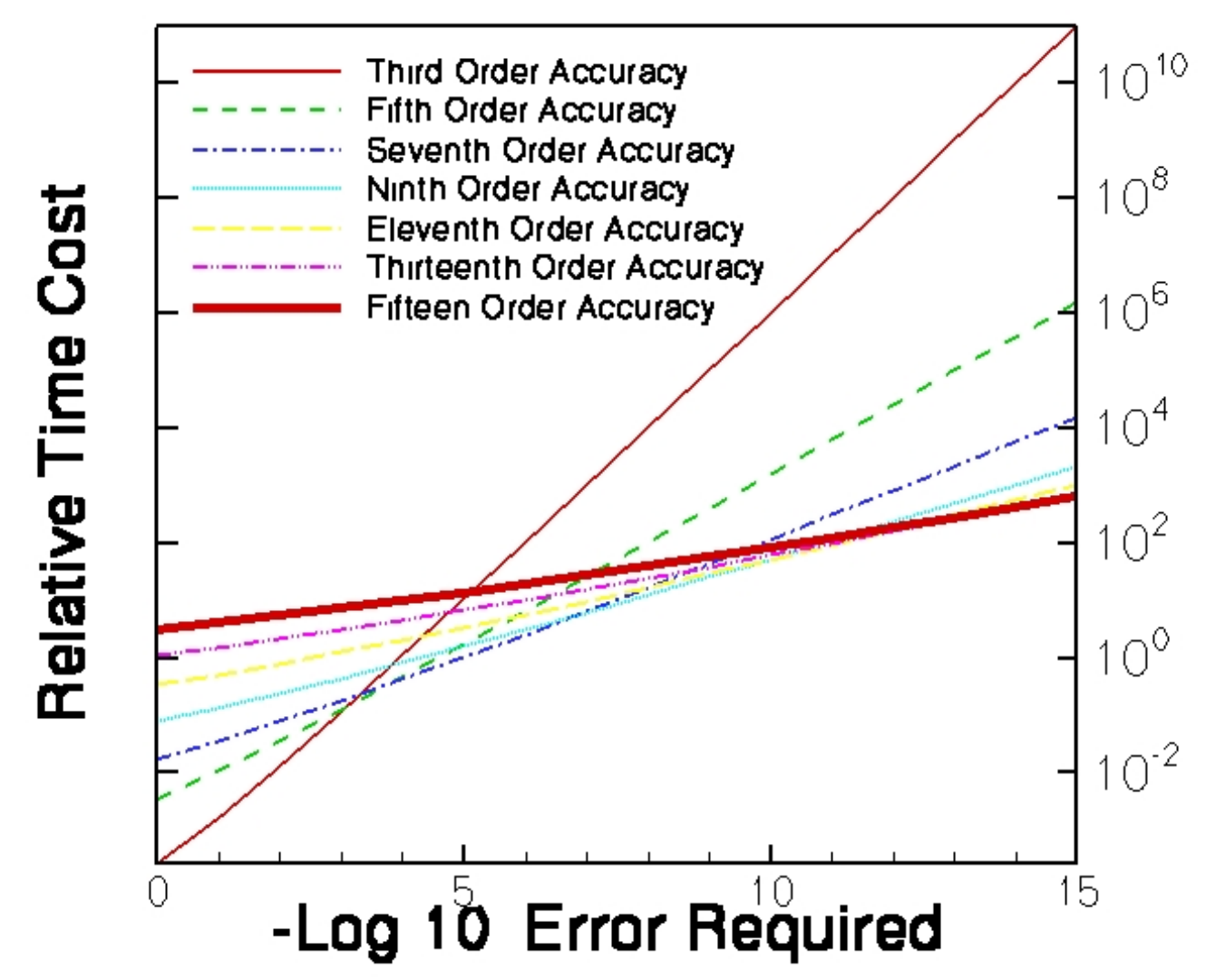




\section{Computational Domain Schematic}

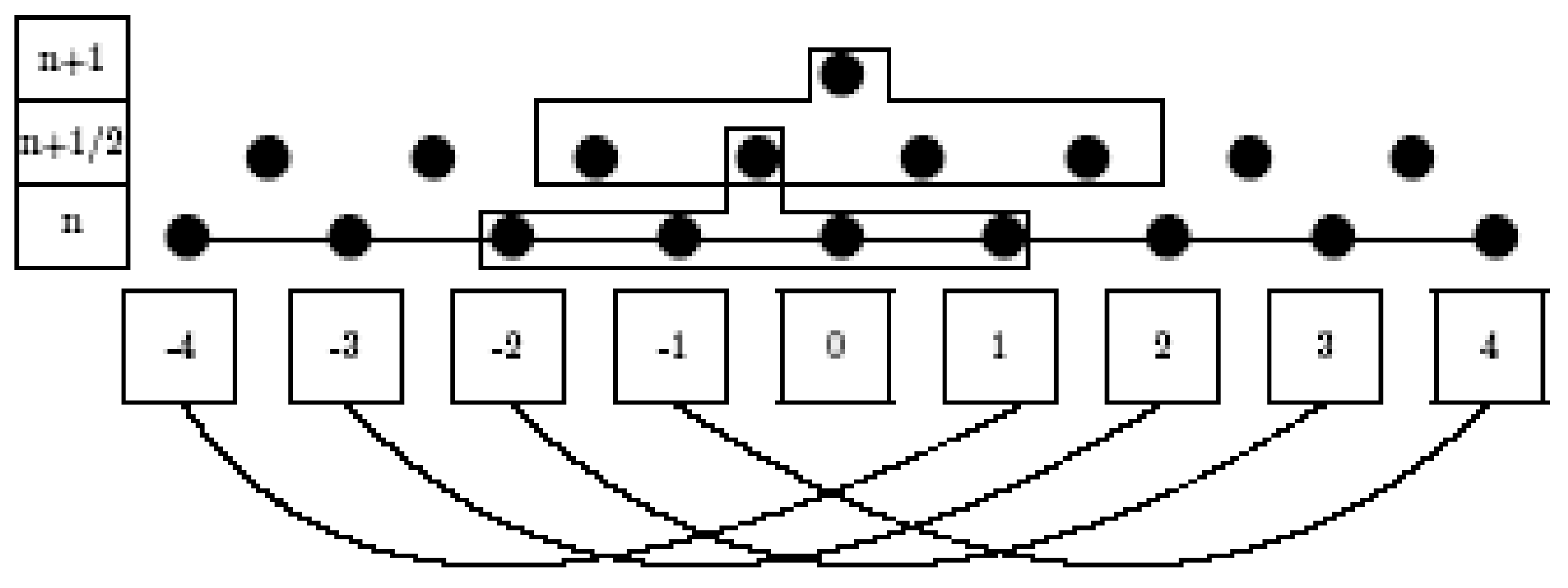




\section{Amplification Factor Comparison}
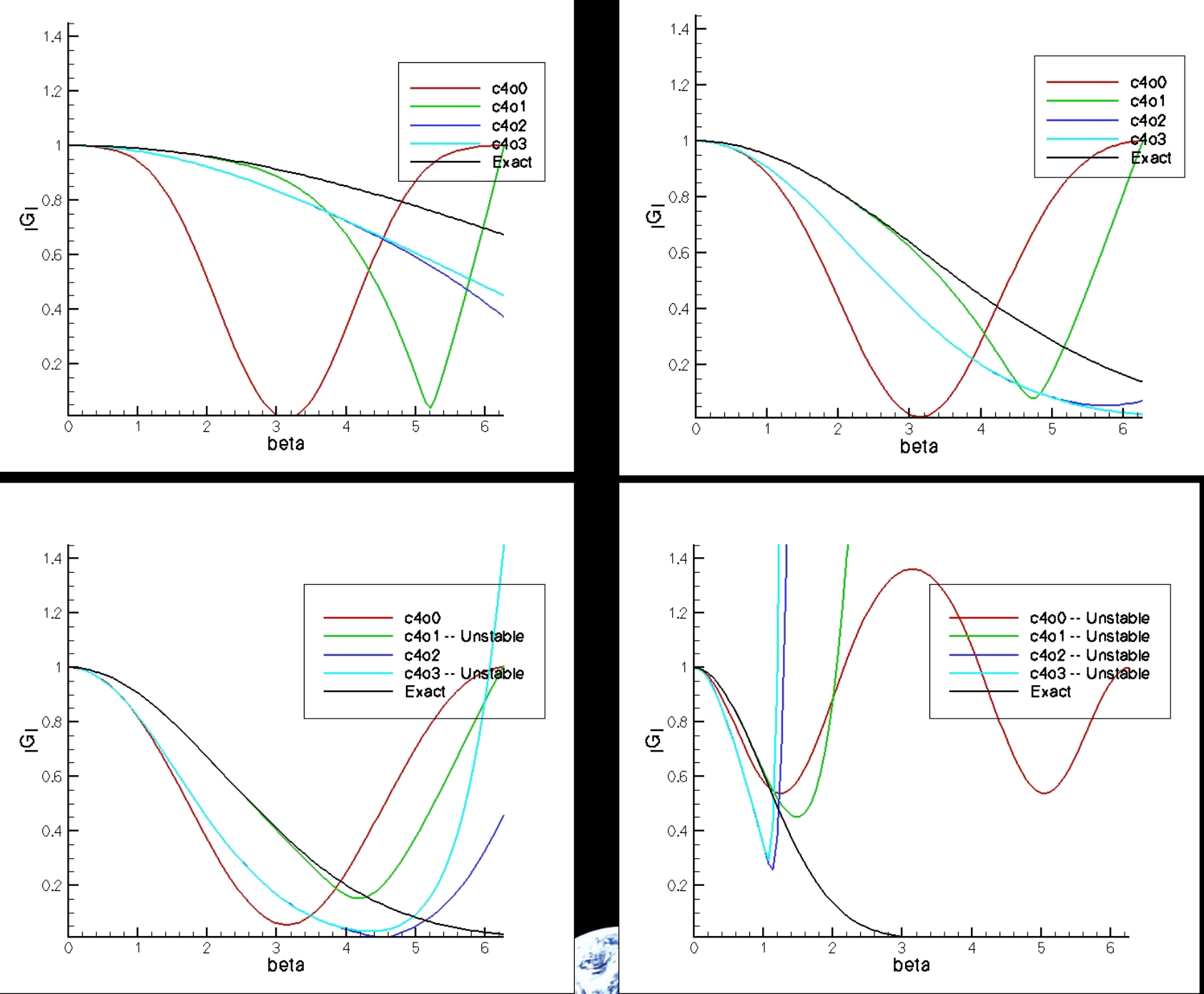


\section{UHF Stability Range}
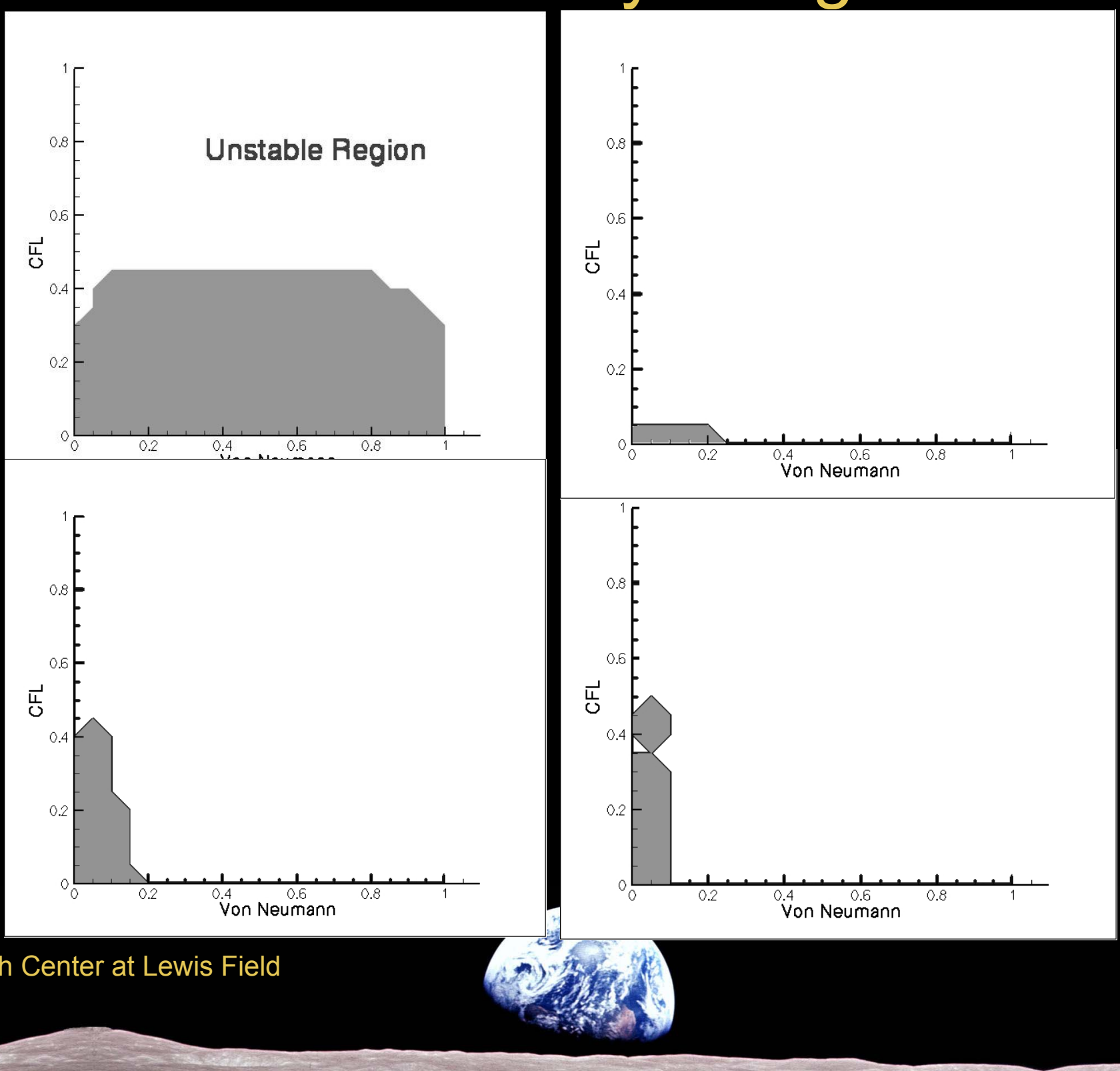


\section{Overview of Segregated Solution}

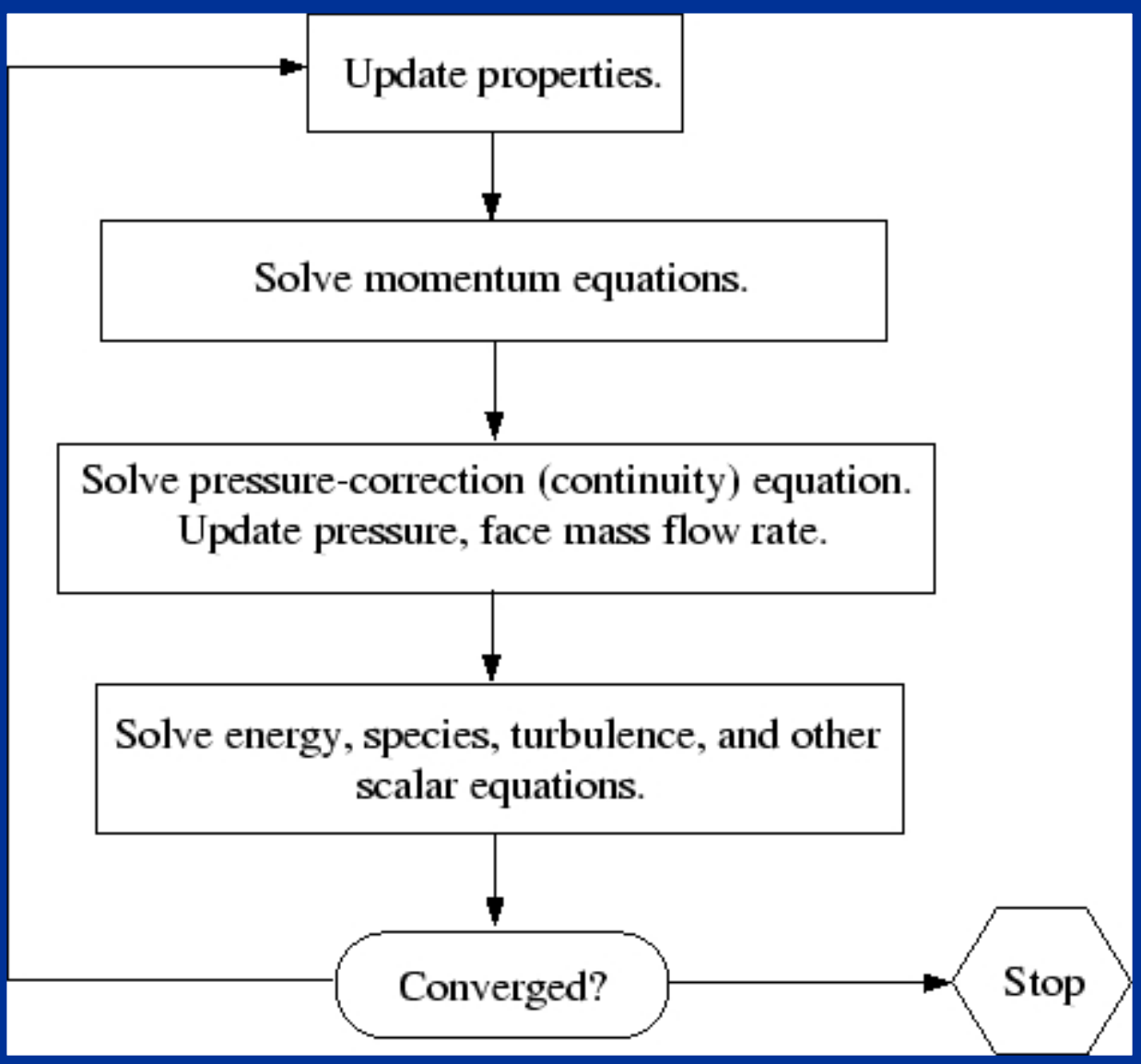




\section{Heat Transfer Test}

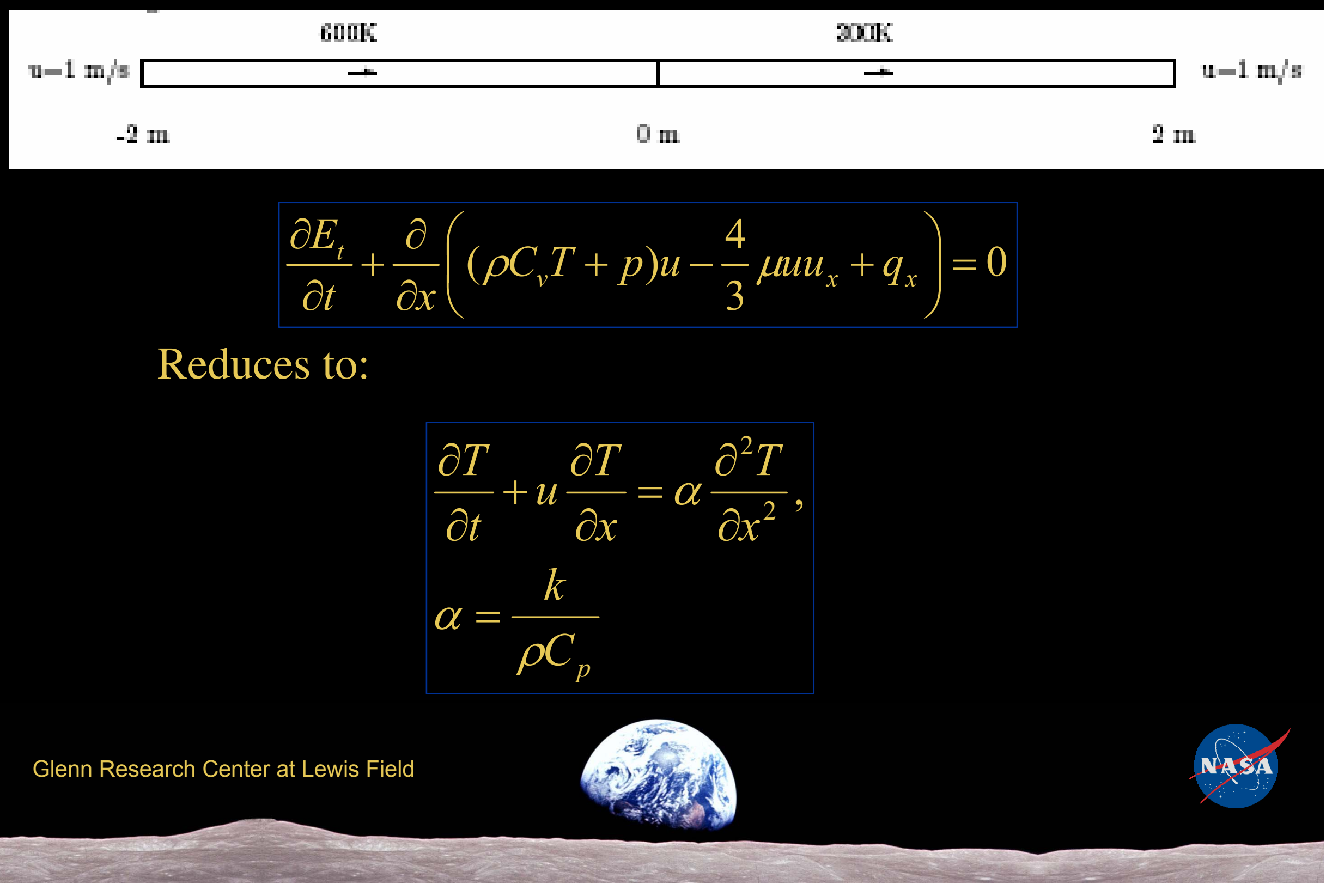




\section{Comparison of Commercial \& Advanced}
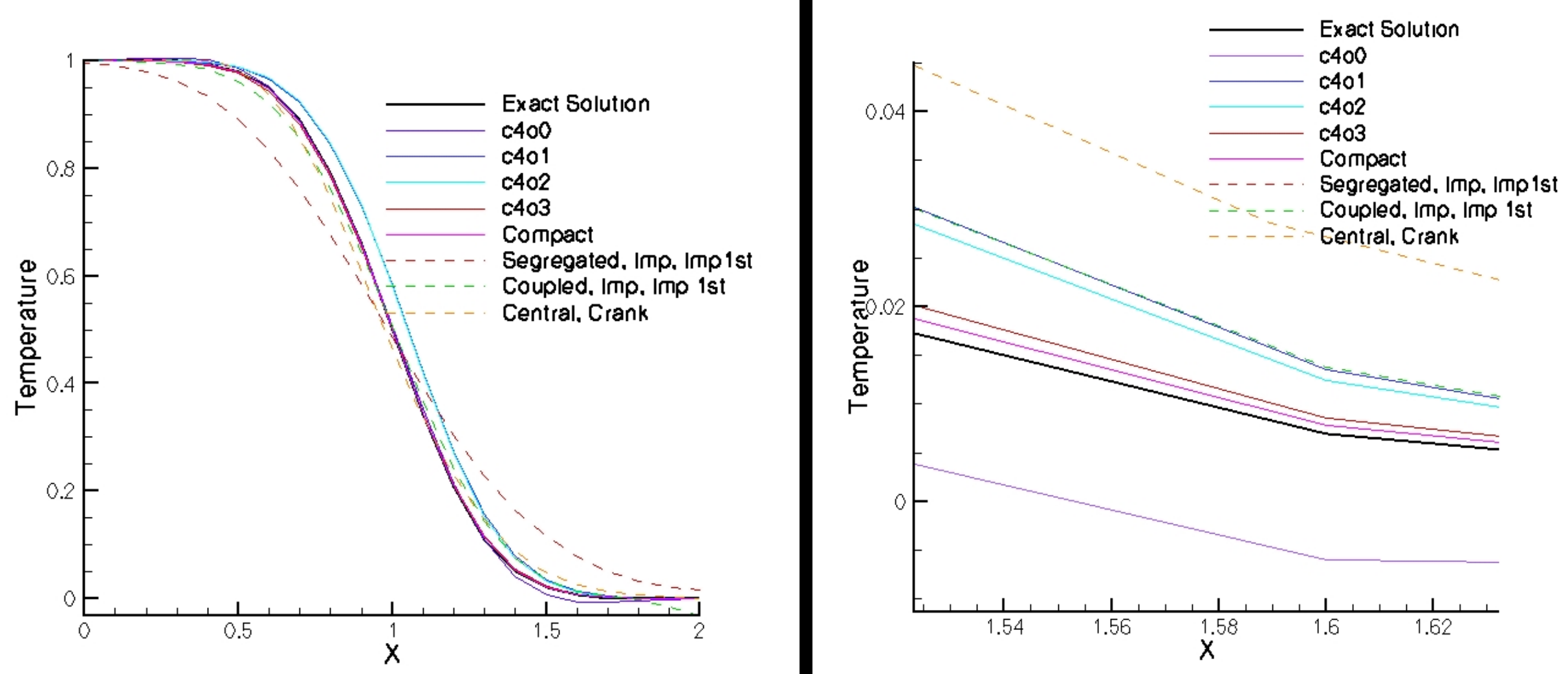


\section{Commercial Comparison}

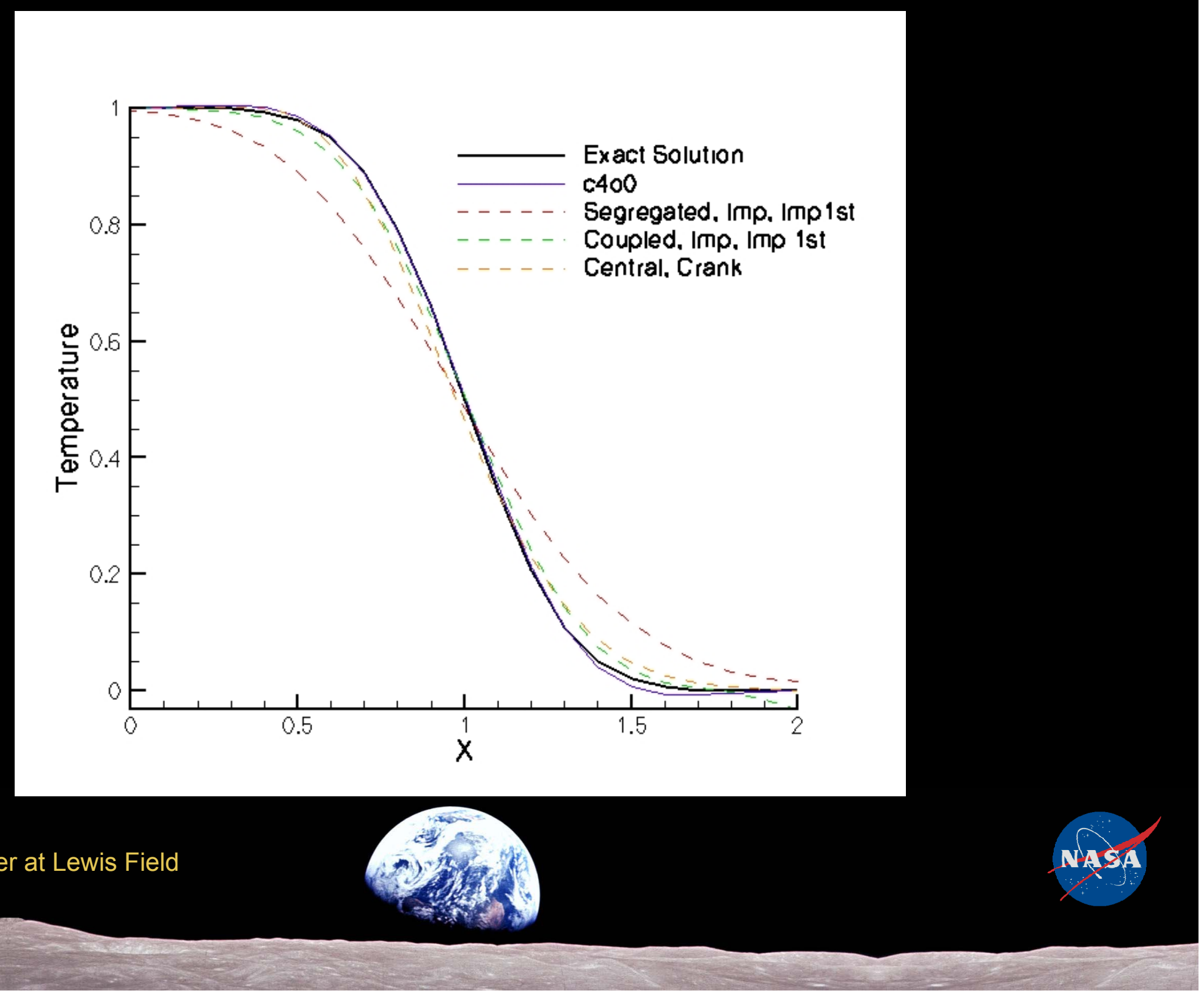




\section{Turbulence Transition Efficiency}

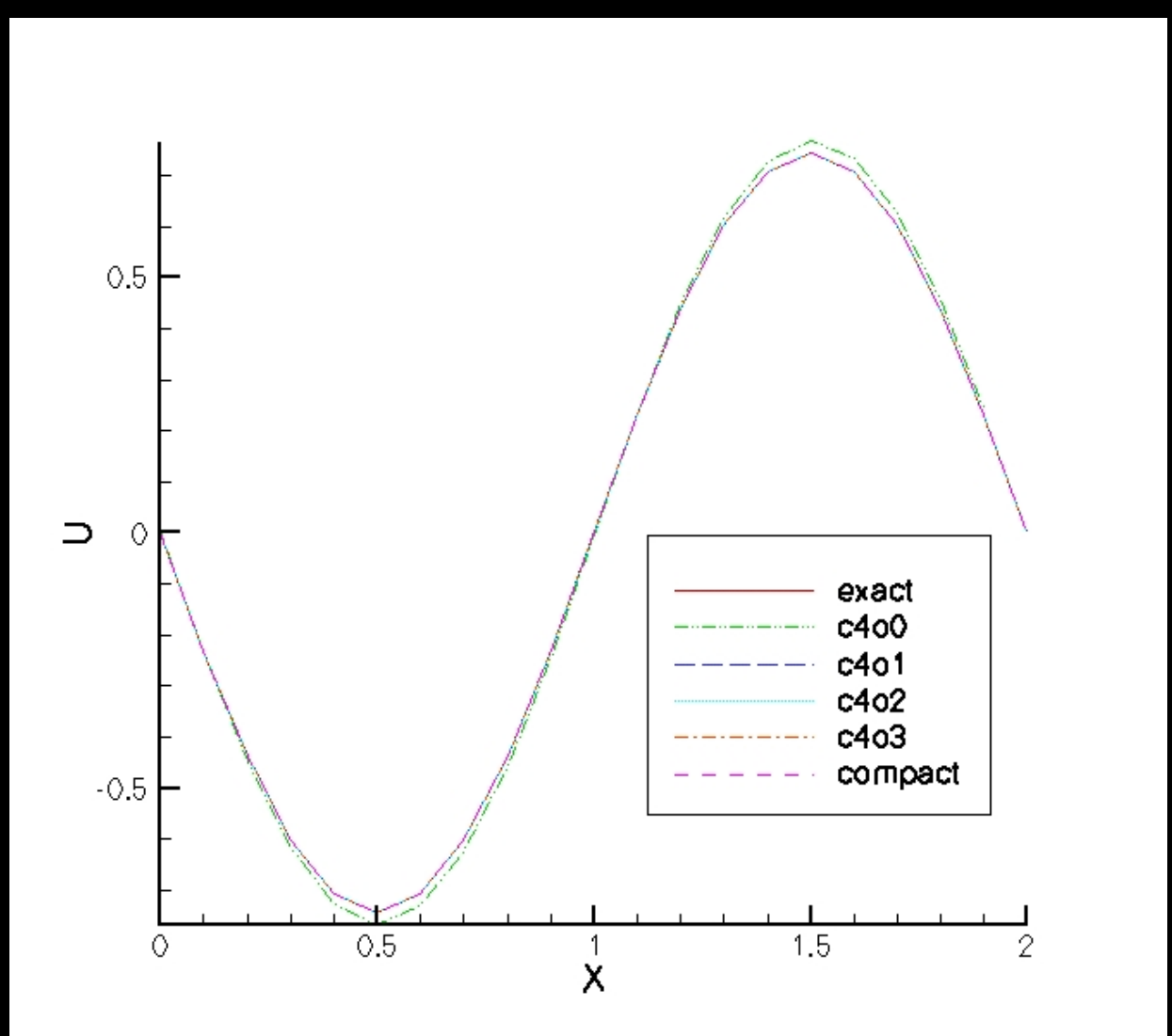

\begin{tabular}{|c|c|c|}
\hline Method & Spaing & Error \\
\hline 8400 & .1 & $2.542610^{-T}$ \\
\hline 400 & .2 & $4.27 \operatorname{tos} 10^{-2}$ \\
\hline 400 & .4 & $4.685710^{-9}$ \\
\hline 401 & .1 & $3.1116210^{-6}$ \\
\hline 401 & .2 & $2.0605110^{-5}$ \\
\hline 401 & .4 & $8.4 \mathrm{Ka} 1 \mathrm{10}^{-1}$ \\
\hline 8402 & .1 & $1.017810^{-10}$ \\
\hline 402 & .2 & $3.192510^{-9}$ \\
\hline 402 & .4 & 6.4100010 \\
\hline 403 & .1 & $34416010^{-15}$ \\
\hline 402 & .2 & $227 \mathrm{BE} \mathrm{ID}^{-1 \mathrm{~s}}$ \\
\hline 4402 & .4 & $31202 \mathrm{~s} \mathrm{ID}^{-11}$ \\
\hline omprest & .1 & $1.090210^{-g}$ \\
\hline omprat & .2 & $7.109610^{-5}$ \\
\hline ompat & .4 & $5.3124010^{-a}$ \\
\hline
\end{tabular}




\section{Points per Kolmogorov Wavelength}

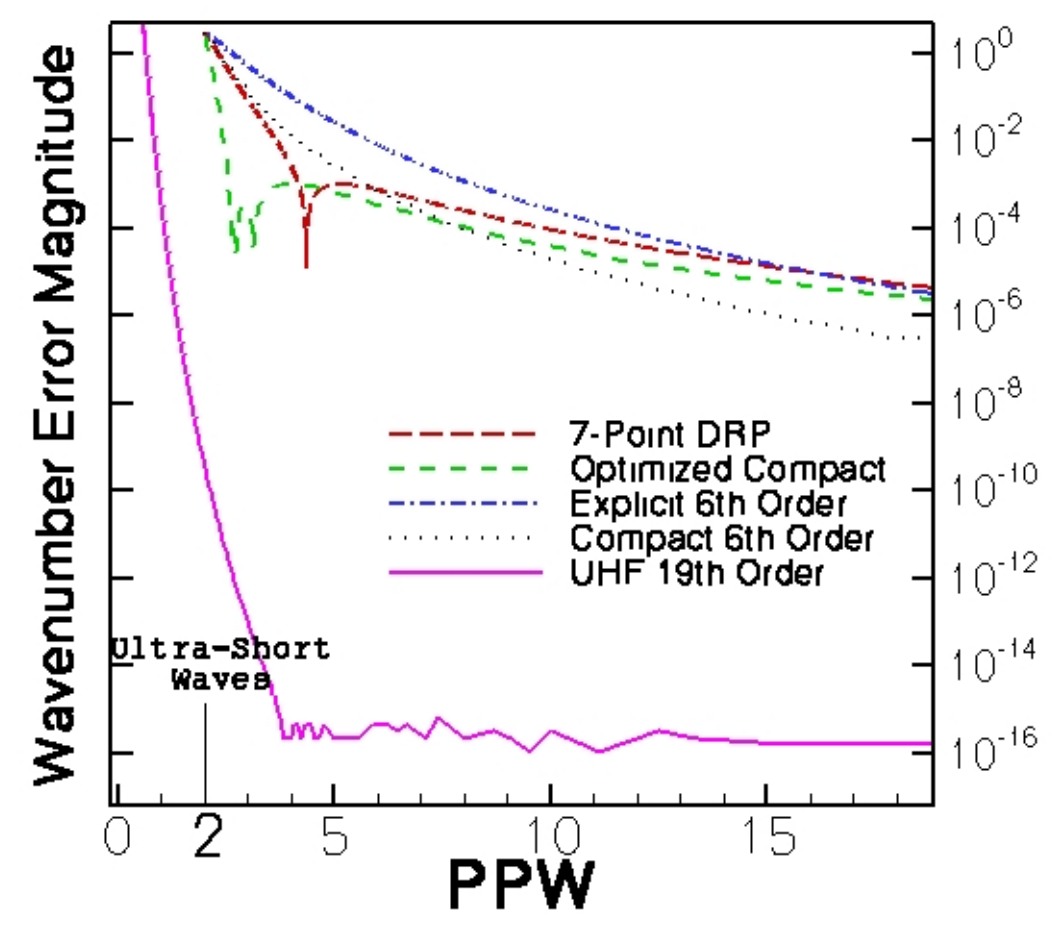




\section{Wave Equation Amplification}

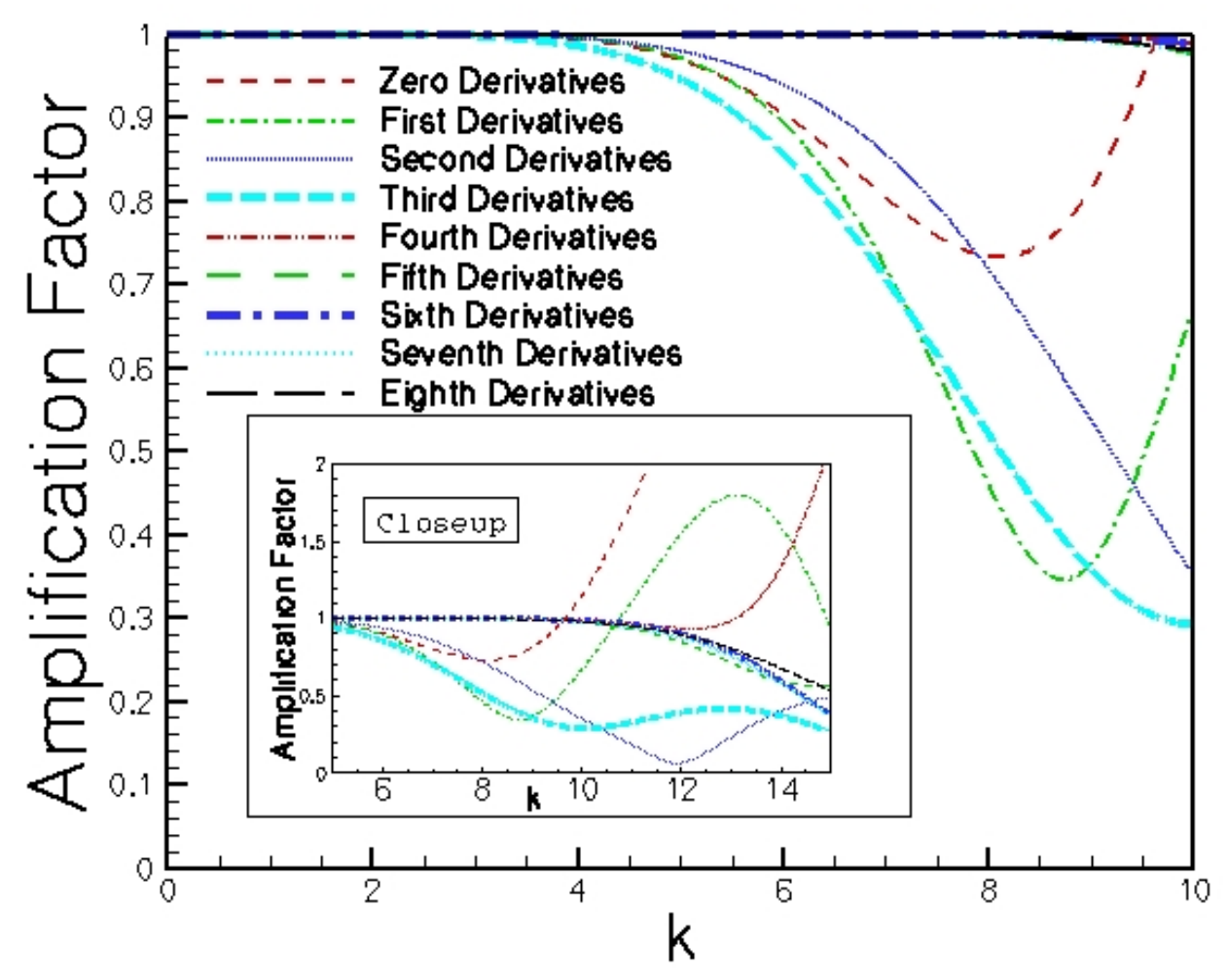




\section{Aliased Frequency Amplification}

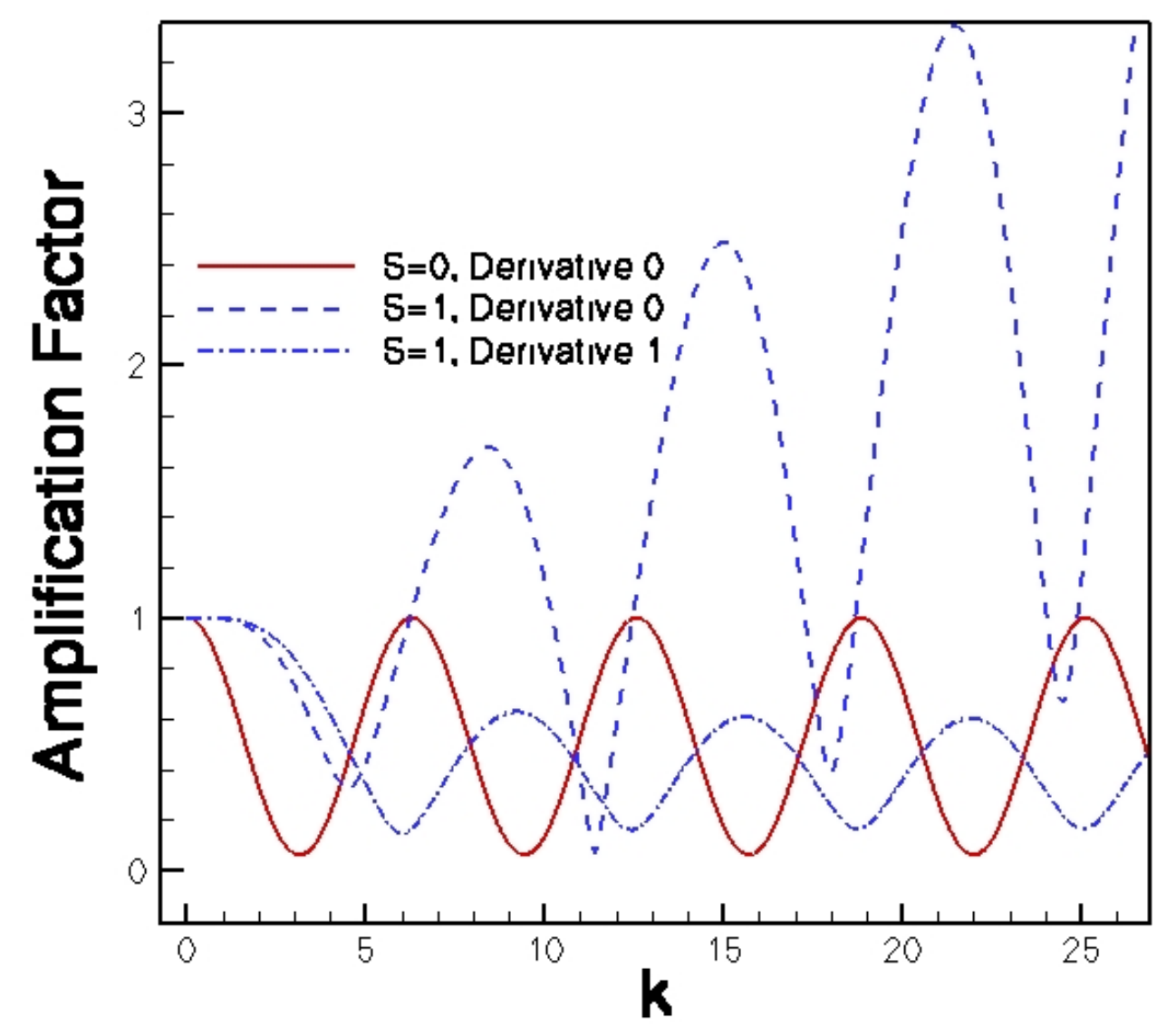




\section{Conclusions}

- Low Reynold's number, wall bounded flow allows economical use of large eddy simulation for turbulent transition modeling

- UHF and Compact comparable at conjugate heat transfer

- UHF much better for turbulence modeling

- Modern methods much more efficient than those currently available commercially 


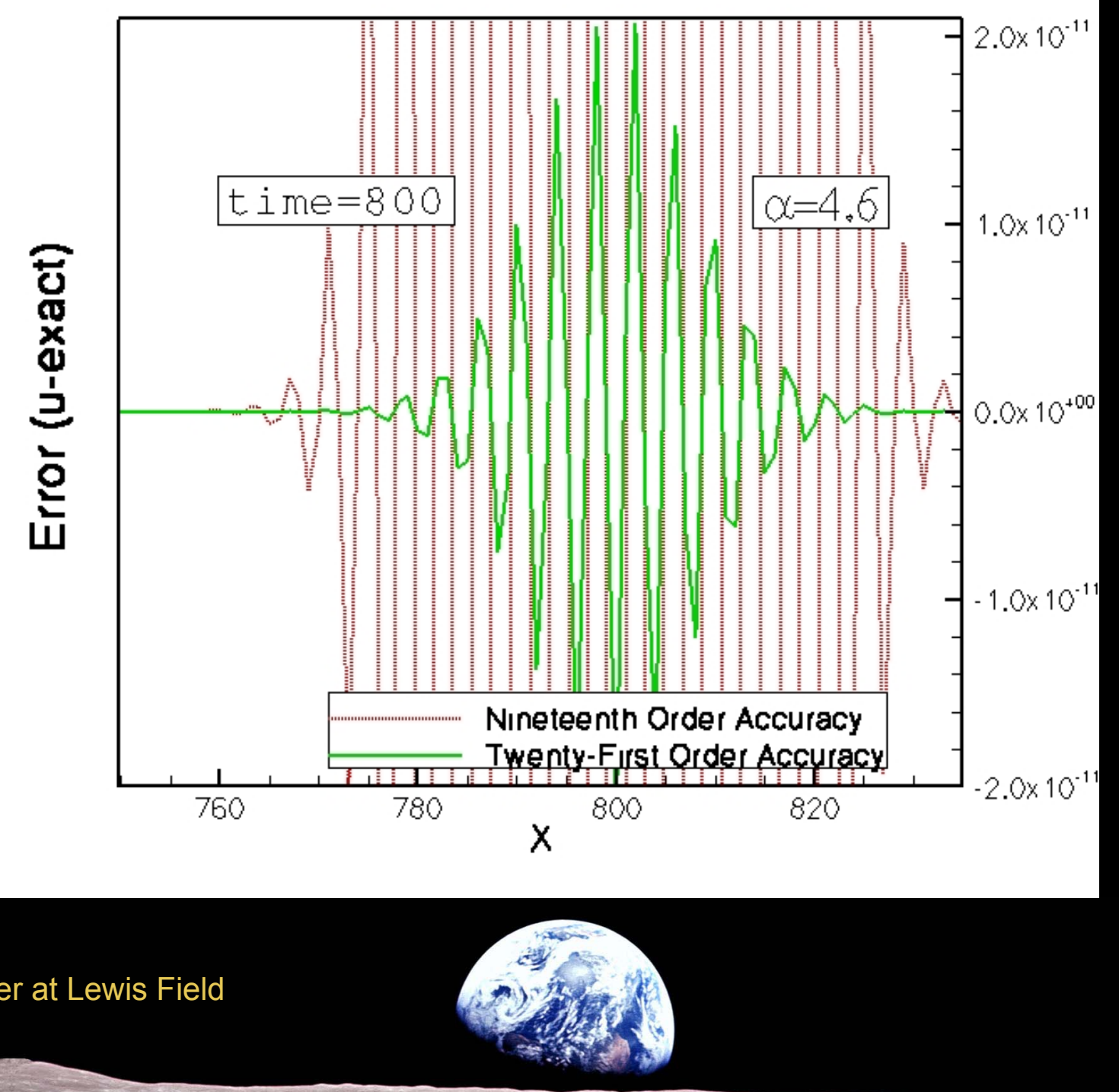




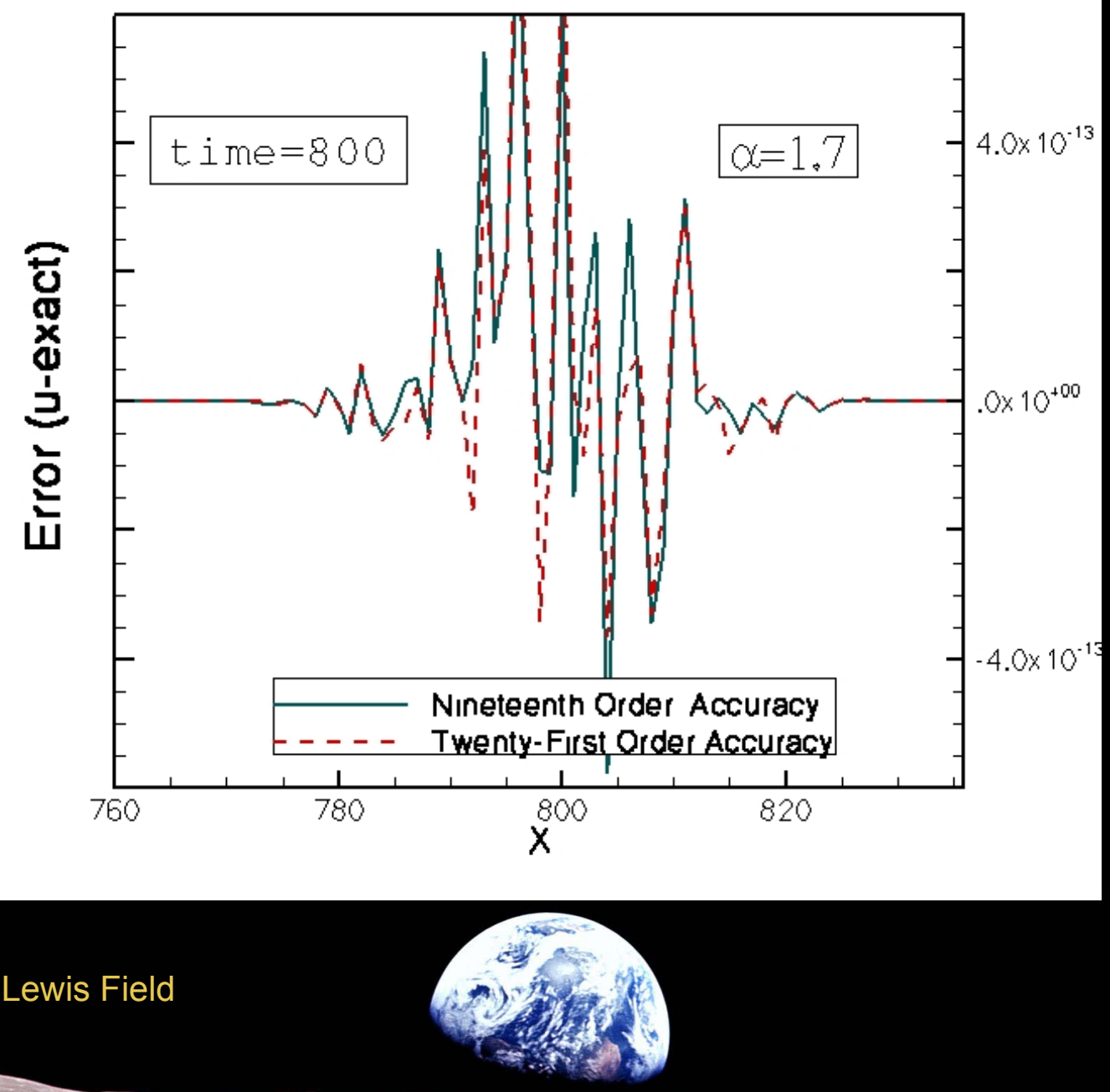




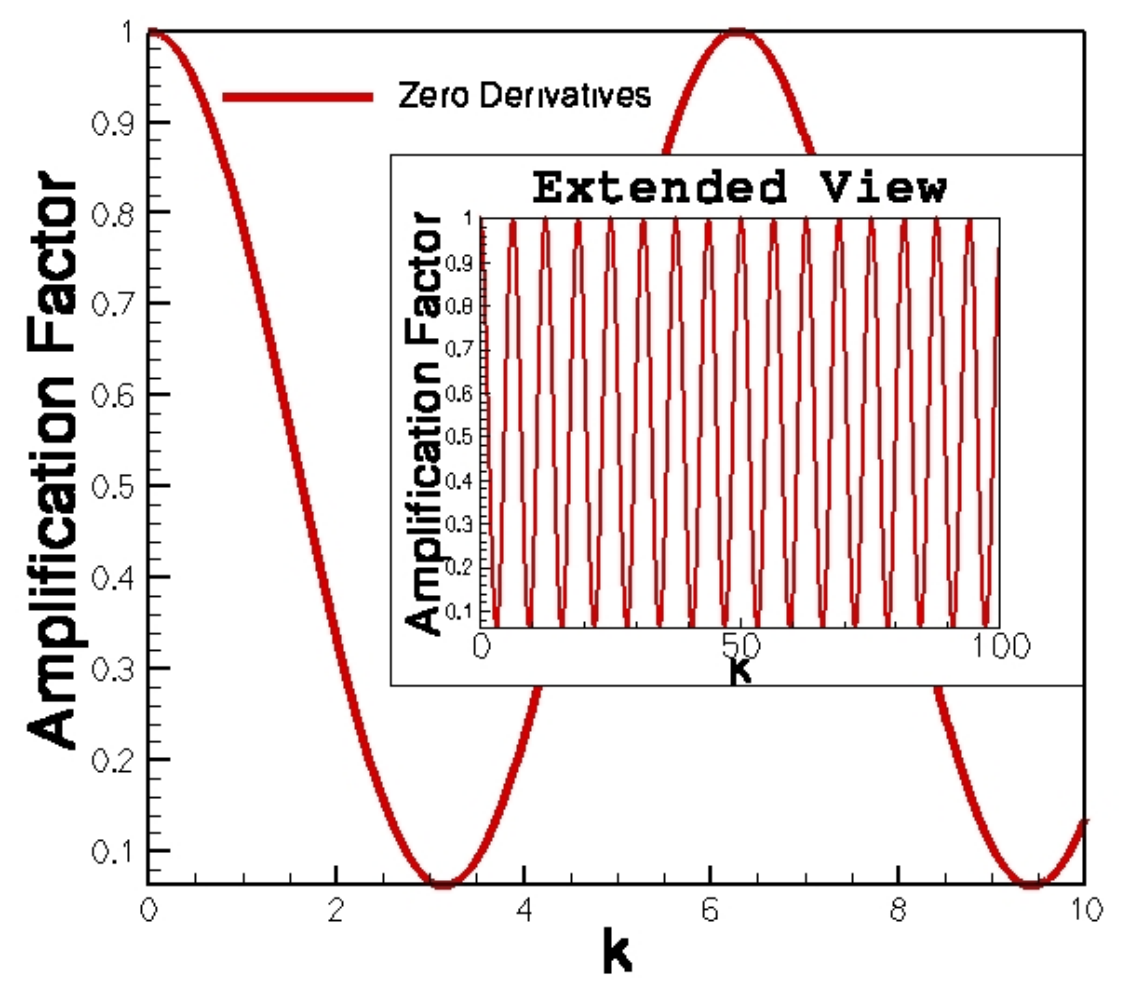




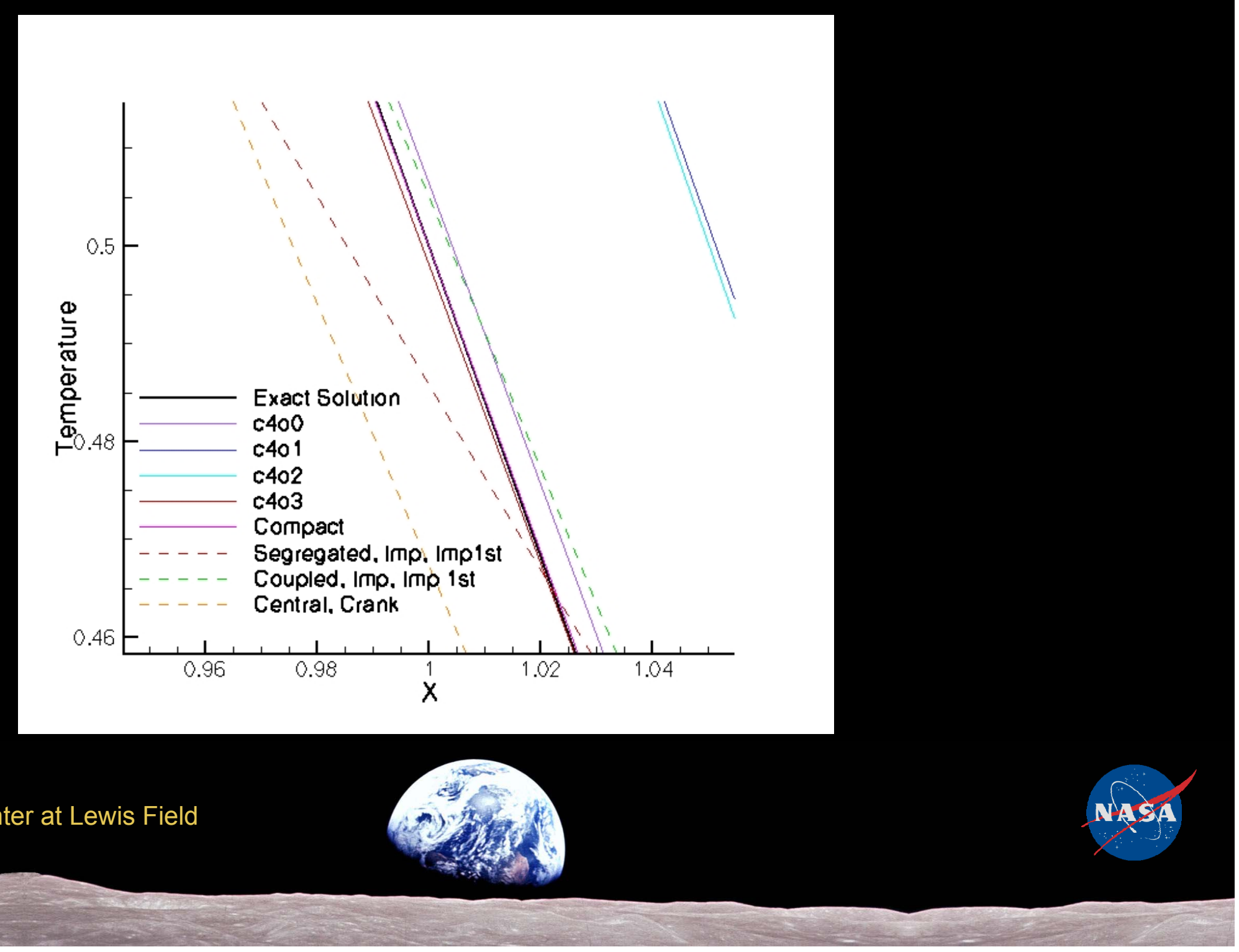




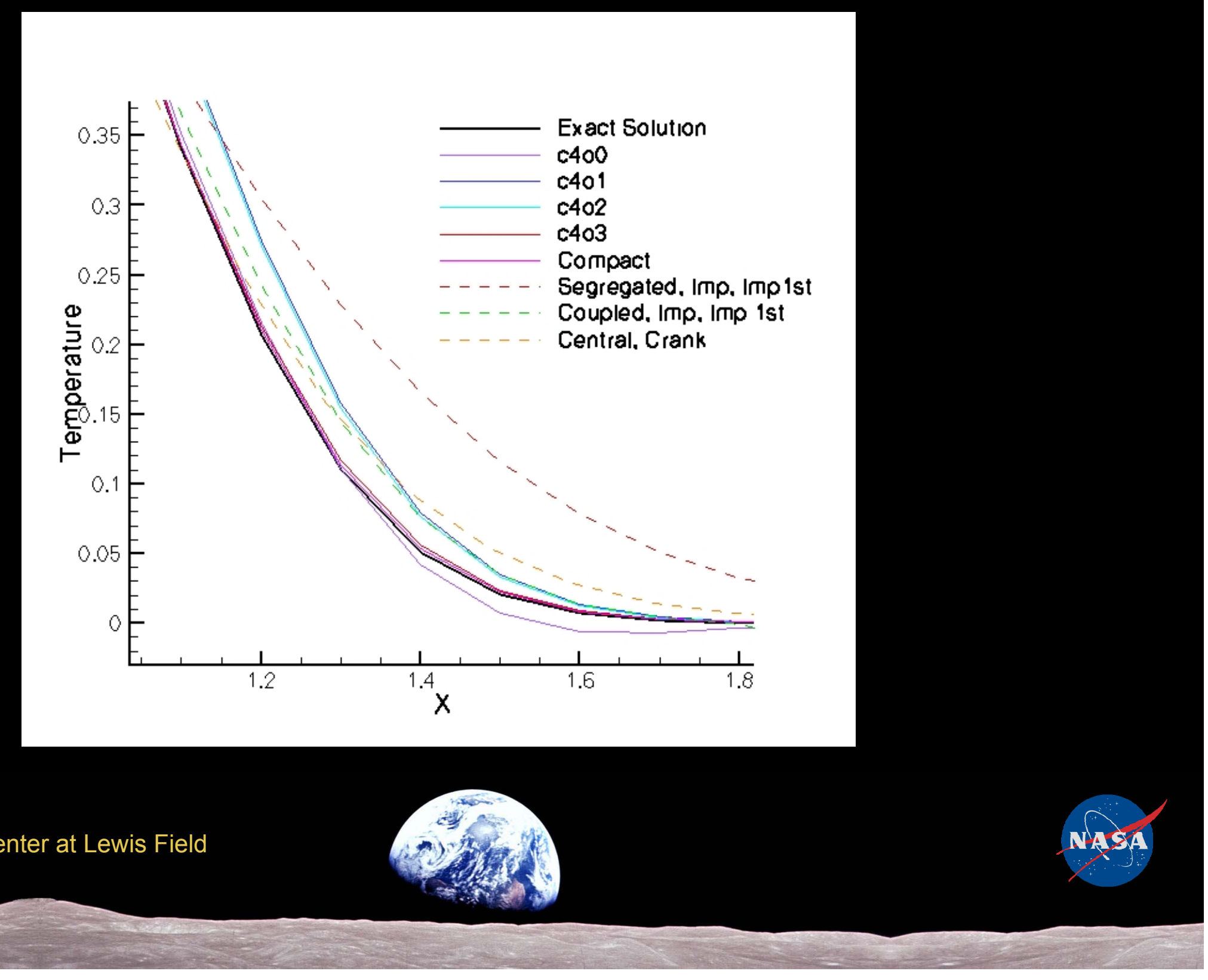




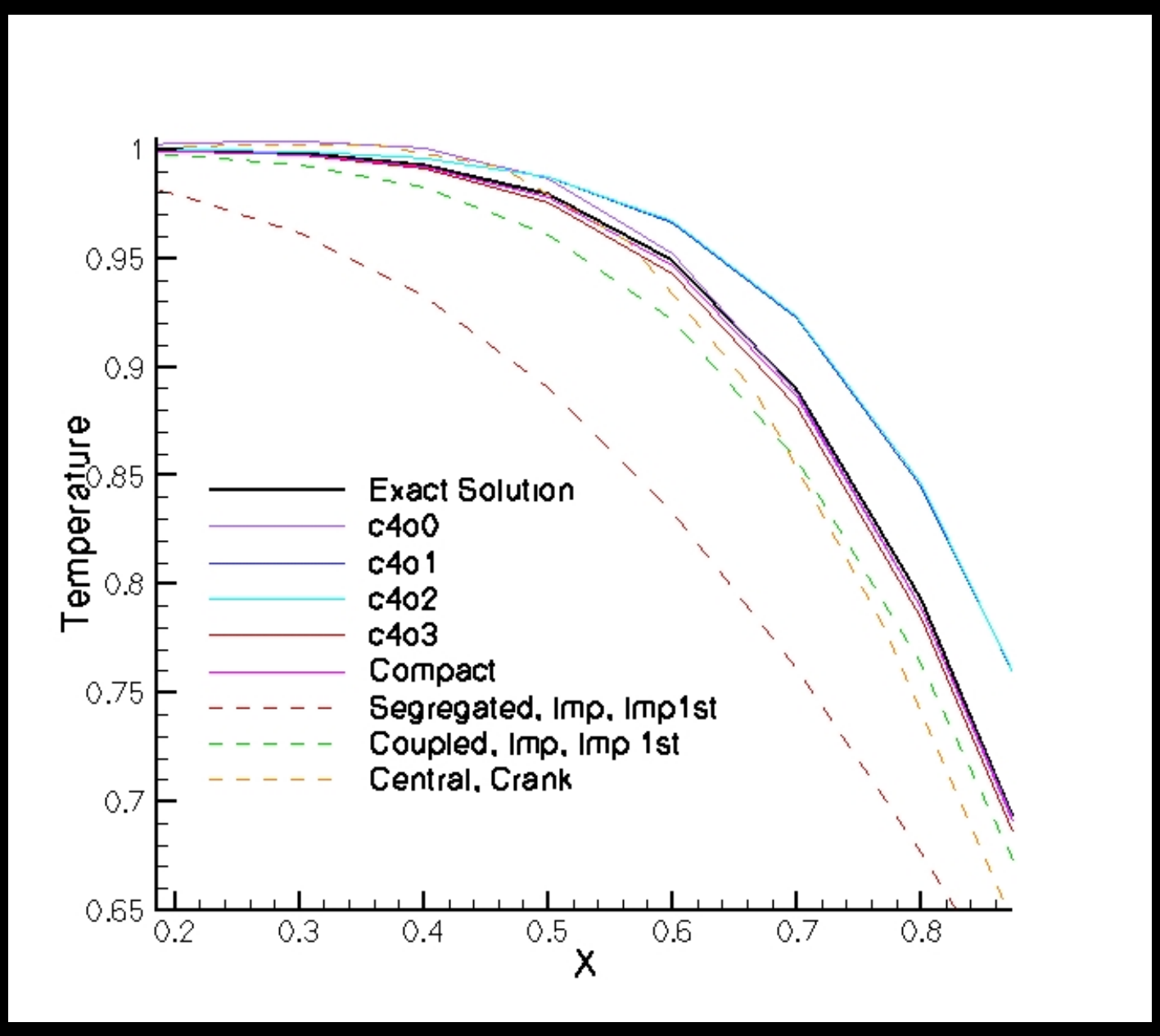




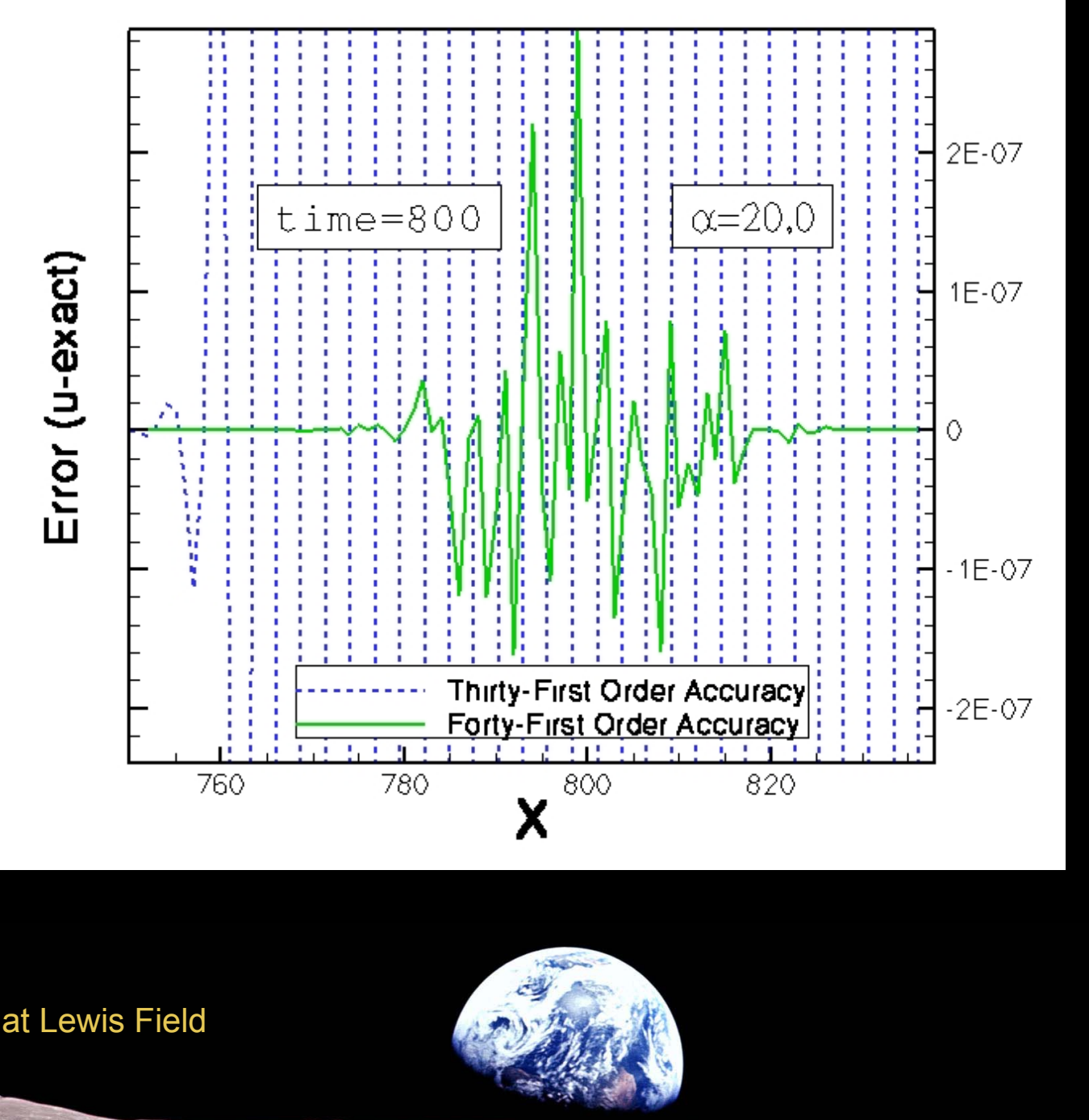

